\title{
Performance in normal subjects on a novel battery of driving-related sensory-motor and cognitive tests
}

\author{
CARRIE R. H. INNES \\ Van der Veer Institute for Parkinson's and Brain Research, Christchurch, New Zealand \\ University of Otago, Christchurch, New Zealand \\ and Christchurch Hospital, Christchurch, New Zealand \\ RICHARD D. JONES \\ Van der Veer Institute for Parkinson's and Brain Research, Christchurch, New Zealand \\ University of Otago, Christchurch, New Zealand \\ Christchurch Hospital, Christchurch, New Zealand \\ and University of Canterbury, Christchurch, New Zealand \\ TIM J. ANDERSON \\ Van der Veer Institute for Parkinson's and Brain Research, Christchurch, New Zealand \\ University of Otago, Christchurch, New Zealand \\ and Christchurch Hospital, Christchurch, New Zealand \\ SuSAN G. Hollobon \\ Burwood Hospital, Christchurch, New Zealand \\ AND \\ John C. DALRYMPle-AlFord \\ Van der Veer Institute for Parkinson's and Brain Research, Christchurch, New Zealand \\ and University of Canterbury, Christchurch, New Zealand
}

\begin{abstract}
Currently, there is no international standard for the assessment of fitness to drive for cognitively or physically impaired persons. A computerized battery of driving-related sensory-motor and cognitive tests (SMCTests) has been developed, comprising tests of visuoperception, visuomotor ability, complex attention, visual search, decision making, impulse control, planning, and divided attention. Construct validity analysis was conducted in 60 normal, healthy subjects and showed that, overall, the novel cognitive tests assessed cognitive functions similar to a set of standard neuropsychological tests. The novel tests were found to have greater perceived face validity for predicting on-road driving ability than was found in the equivalent standard tests. Test-retest stability and reliability of SMCTests measures, as well as correlations between SMCTests and on-road driving, were determined in a subset of 12 subjects. The majority of test measures were stable and reliable across two sessions, and significant correlations were found between on-road driving scores and measures from ballistic movement, footbrake reaction, hand-control reaction, and complex attention. The substantial face validity, construct validity, stability, and reliability of SMCTests, together with the battery's level of correlation with on-road driving in normal subjects, strengthen our confidence in the ability of SMCTests to detect and identify sensory-motor and cognitive deficits related to unsafe driving and increased risk of accidents.
\end{abstract}

Ability to drive a motor vehicle is very important for most adults. Loss of a driving licence has been linked to regret, loneliness, decreased self-esteem, isolation, depression, decreased social and recreational activities, and reduced overall quality of life (Johnson, 1999; Legh-Smith, Wade, \& Hewer, 1986; Taylor \& Tripodes, 2001; Wiseman \& Souder, 1996). Unfortunately, physical or cogni- tive deficits, such as those observed following traumatic brain injury, stroke, neurodegenerative disease, or aging, often decrease a person's ability to drive safely (Hawley, 2001; Hunt, Morris, Edwards, \& Wilson, 1993; Lings \& Jensen, 1991; Wood, Worringham, Kerr, Mallon, \& Silburn, 2005). When conducting medical examinations, medical practitioners are commonly responsible for mak-

C. R. H. Innes, carrie.innes@vanderveer.org.nz 
ing judgments regarding their patients' medical fitness to drive. Whereas most countries allow for voluntary reporting, medical practitioners in some U.S. states are required by law to report drivers who have medical or functional impairments affecting safe driving ability to the appropriate licensing agency (Berger, Rosner, Kark, \& Bennett, 2000; Wang, Kosinski, Schwartzberg, \& Shanklin, 2003), as are those in some Canadian provinces (Berger et al., 2000) and Australian states (Austroads, 2006), as well as in New Zealand (Land Transport Safety Authority, 2002). When there is doubt regarding an individual's fitness to drive, practitioners in most countries refer the patient to a specialist driving assessment service. In New Zealand, approximately 35 per 100,000 drivers are referred for specialist driving assessment each year due to brain lesions or age-related cognitive decline. However, currently, there is no international standard for the assessment of fitness to drive for cognitively or physically impaired persons.

We have developed a battery of computerized sensorymotor and cognitive tests (SMCTests) as an assessment tool in neurology and neurorehabilitation, with particular application to the assessment of driving abilities in patients with neurological disorders. To increase user compliance and encourage optimal prediction of on-road performance, the tests and apparatus were designed to be contextually close to the driving task, providing higher face validity than other standard physical assessments and neuropsychological tests.

SMCTests forms the off-road assessment at the Driving and Vehicle Assessment Service (DAVAS) in Christchurch. The sensory-motor tests from the SMCTests battery have proven valuable in (1) quantification of sensory-motor deficits in persons with neurological disorders (DalrympleAlford, Kalders, Jones, \& Watson, 1994; Heitger et al., 2004; Heitger et al., 2006; Jones \& Donaldson, 1995; Jones, Donaldson, \& Parkin, 1989; Jones, Donaldson, Parkin, \& Coppage, 1990; Jones, Donaldson, \& Sharman, 1996; Jones, Donaldson, \& Timmings, 1992; Jones, White, Lawson, \& Anderson, 2002; Muir, Jones, Andreae, \& Donaldson, 1995; Watson, Jones, \& Sharman, 1997); (2) determination of the effects of alcohol, time of day, age, sex, and handedness on sensory-motor performance (Dalrymple-Alford, Kerr, \& Jones, 2003; Jones, Williams, $\&$ Wells, 1986); (3) investigation of the characteristics and detection of microsleeps during a sustained visuomotor task (Davidson, Jones, \& Peiris, 2007; Peiris, Jones, Davidson, Carroll, \& Bones, 2006); and (4) validation of computational models of the brain (Davidson, Jones, Andreae, \& Sirisena, 2002; Davidson, Jones, Sirisena, \& Andreae, 2000). However, they can provide only limited quantification of the higher mental functions that are important in the driving task. Thus, six cognitive tests were developed and added to form SMCTests: Complex Attention, Visual Search, Decision-Making, Impulse Control, Planning, and Divided Attention (Innes et al., 2007). Following an evaluation of the literature, deficits in these six cognitive functions were identified as those most frequently identified subjectively during on-road assessments of subjects with brain disorders (e.g., Heikkilä, Turkka, Korpelainen, Kallanranta, \& Summala, 1998; Korteling, 1990; Staplin,
Gish, Decina, Lococo, \& McKnight, 1998; Wild \& Cotrell, 2003; Wilson \& Smith, 1983) and associated with previous incidents of unsafe driving or on-road driving assessment outcome (e.g., Galski, Bruno, \& Ehle, 1993; Mazer, Korner-Bitensky, \& Sofer, 1998; McKnight \& McKnight, 1999; Schanke \& Sundet, 2000).

The ability of the combined battery of sensory-motor and cognitive tests to predict on-road driving ability was initially assessed in a group of 50 subjects referred to DAVAS who had been diagnosed with various brain disorders (Innes et al., 2007). A binary logistic regression model identified measures from planning, complex attention, sine tracking, ballistic movement, and divided attention as being predictive of on-road driving and correctly classified 47 of the 50 referrals as "pass" or "fail" on an on-road assessment (i.e., 94\% accuracy). The utility of SMCTests for predicting on-road driving ability in persons with brain disorders has been shown, but normal baseline performance data are also required. The present study provides normative performance data, construct validity, and face validity analysis of SMCTests from 60 normal, healthy subjects across three age groups: $18-40$ years, $41-60$ years, and $61-80$ years. Test-retest stability and reliability of the novel cognitive tests were determined in a separate subset of 12 subjects. Correlations between SMCTests performance and on-road driving performance were also assessed in a separate subset of 12 subjects.

\section{METHOD}

\section{Subjects}

Sixty subjects ( 30 female) were recruited through personal contacts and a newspaper advertisement and were evenly split among three age groups: younger group (mean age $=29.8$ years, range $=$ $22-37$ ), middle-aged group (mean age $=50.5$ years, range $=41-$ 60 ), and older group (mean age $=70.3$ years, range $=62-78$ ). All subjects had held a current, full driver's license for a minimum of 3 years $(M=30.8$, range $=3-65)$. No subject had suffered any form of brain injury or had any diagnosed psychiatric, neurological, or musculoskeletal disorder. Ethical approval for the study was obtained through the Canterbury Ethics Committee.

\section{Apparatus}

Subjects undertook SMCTests in a modified car body interfaced to a Pentium PC. They used the steering wheel, indicator, accelerator, clutch, brake pedals, and hand controls to respond to large $(80 \times$ $60 \mathrm{~cm}$ ) computer-generated test stimuli displayed by a data projector on a facing wall, with an eye-to-screen distance of $180 \mathrm{~cm}$ (visual angle, $11.3^{\circ}$ ). The SMCTests program generated the tests and stored and analyzed the performance data.

Off-road assessment. The off-road assessment for the study consisted of the battery of sensory-motor tests, the battery of newly developed cognitive tests, and a comparison battery of standard neuropsychological cognitive tests. ${ }^{1}$

Sensory-motor tests. The sensory-motor tests are described in detail elsewhere (Christchurch Neurotechnology Research Programme [CNRP], 2006; Heitger et al., 2004; Jones, 2006; Jones \& Donaldson, 1995; Jones et al., 1989; Jones, Sharman, Watson, \& Muir, 1993). They include three visuoperceptual tests, four visuomotor tests, and three eye-arm tracking tests. The three visuoperceptual tests were Visual Resolution, which measured the minimum separation at which a subject was able to identify a dot as being off the center of a vertical line; Static Perception, which measured the minimum separation at which a subject was able to identify the tip of an arrow as being off a vertical line or a sinusoidal waveform; and 
Dynamic Perception, which measured the minimum separation between the point of an arrow and a moving random preview target at which a subject was able to perceive the tip of an arrow as being off the target (as in Figure 1A but without the four horizontally pointing arrows).

The four visuomotor tests were Ballistic Movement, which measured the reaction time and maximum speed at which a subject could turn the steering wheel to move an arrow out of a box and across a pass-line in response to an unpredictable signal (3- to 7-sec latency); Footbrake Reaction, which measured the reaction and movement times at which a subject could respond to an unpredictable signal (2to 6-sec latency) by moving his or her foot from the accelerator to the brake; Footbrake and Clutch Reaction, which measured the reaction latency and movement times at which a subject could respond to an unpredictable signal by releasing the accelerator and pressing both the clutch and brake pedals; and Hand Control Reaction, which measured the reaction and movement times at which a subject could respond to an unexpected signal by pushing back on a hand control lever.

The three eye-arm tracking tests measured the accuracy with which a subject could track a laterally moving target (preview of $8 \mathrm{sec}$ ), using the steering wheel to move a horizontally moving arrow. The tracking target was either a sine wave (sine tracking) or a random wave (random tracking) (as in Figure 1A but without the four horizontally pointing arrows), or it jumped to the left or right (step tracking).

Driving-related cognitive tests. The driving-related cognitive tests are described in detail elsewhere (CNRP, 2006).

The Divided Attention test assessed ability to divide attention between two simultaneous visuocognitive tasks (Figure 1A). The test combined the preview random tracking task with a simultaneous visual scanning task. While the subject tracked the random target with the steering wheel, 12 consecutive sets of four arrows were displayed on the screen. The subject was required to maintain accurate tracking of the target while scanning the arrows and determining whether or not all four arrows were pointing in the same direction. The subject was required to respond verbally with "same" if the arrows were pointed in the same direction or "different" if they were not. This verbal response was recorded by an assessor by pressing the "S" or " $D$ " button, respectively, on the keyboard. Each set of arrows was displayed on the screen for $4.8 \mathrm{sec}$, with a 1 -sec delay between sets. Subjects were previously tested separately on the tracking and arrow perception tasks in order to obtain baseline performance on the component tasks.

The Complex Attention test assessed complex attention function (Figure 1B). The subject moved the steering wheel to maintain an arrow in a box on the same side of the screen as a green-light symbol. The light symbol alternated between the left and right side of the screen and required the subject to turn the steering wheel from left to right repeatedly. Each green light was presented for 3 to $5 \mathrm{sec}$. Reaction and movement times were measured to give indications of slowed information processing, mental and physical fatigue, and lapses in concentration.

The Impulse Control test assessed ability to exercise anticipatory and inhibitory control (Figures 1C and 1D). The subject depressed the accelerator pedal to activate a green light (simulating simplified traffic lights) on a screen. When the green light went off (following a random delay of 3-5 sec), the red light came on, and the subject was required to release the accelerator and depress the brake as quickly as possible. In 10 of the 45 trials, a purple rather than red light was presented. This was a false stimulus trial for which the subject was asked to keep the accelerator pedal depressed. The presentation of the top light (red or purple) in both standard and false stimulus trials was cued by smaller yellow discs appearing on either side of the top light $500 \mathrm{msec}$ prior to the top light's changing. Incorrect releases of the accelerator in response to false stimulus trials were interpreted as inhibitory errors. In contrast, releases of the accelerator while the green light was still presented (or within $180 \mathrm{msec}$ of the light change) were interpreted as anticipatory errors.

The Visual Search test assessed visual scanning and selective attention, including left-right or central-peripheral vision bias, and comprised 20 trials of static images, each containing 70 road-sign stimuli (Figure 1E). Each screen was presented for a maximum of $10 \mathrm{sec}$. The subject searched each image for 1 of 2 target stimuli-a turn-left arrow and a turn-right - with only 1 of the 2 targets present on any given trial. Examples of the target stimuli were shown in a box at the top of all images. If the turn-left arrow was presented, the subject was required to turn the steering wheel to the left as quickly as possible, and, conversely, to the right for the turn-right arrow.

The Planning test assessed ability to use accurate timing and judgment as an indicator of planning ability. The subject was presented with a screen showing a plan view of a road and its surrounding and was told that he or she was in the blue car near the bottom of the screen (Figure 1F). When the subject pressed the accelerator, the road environment scrolled down the screen at a fixed speed, simulating the subject's car driving forward along the road. The preview time was $18.5 \mathrm{sec}$ and represented scaled equivalents of a $257-\mathrm{m}$ preview distance and a speed of $50 \mathrm{~km} / \mathrm{h}$. The subject used the brake to stop the blue car. The road included four curved sections, and at predetermined intervals, a hazard or crossroad appeared. Subjects were asked to drive as far as possible in $6 \mathrm{~min}$, while avoiding stationary hazards and other cars.

The Decision-Making test assessed accuracy and speed of decision making related to road rules (Figure 1G). The subject was presented with images of a plan view of an intersection involving two or more cars. A blue car near the bottom of the image represented the subject's car, and all other cars were yellow. Orange indicator lights signaled the driving intention of each car. A blue arrow extended from the front of the subject's car to indicate the intended direction of travel. For each screen, the subject had to decide as quickly as possible whether to yield to another car, and do so by pressing the brake, or to proceed, and do so by pressing the accelerator. The 26 trials were split into 12 basic trials (subject's car and one other car) and 14 complex trials (subject's car and three to six other cars).

Standard neuropsychological tests. These tests included the Test of Everyday Attention (Robertson, Ward, Ridgeway, \& NimmoSmith, 1996), Conners' (1995) Continuous Performance Test, and the Tower of Hanoi subtest of the Delis-Kaplan Executive Function System battery (Delis, Kaplan, \& Kramer, 2001a). Five subtests from the Test of Everyday Attention were used in the study: map search, elevator counting, elevator counting with distraction, telephone search, and telephone search dual task. These subtests provided measures of complex attention, divided attention, and visual search. Conners' Continuous Performance Test provided measures of impulse control and sustained attention. The Tower of Hanoi subtest provided a measure of planning.

Normal performance. The 16 SMCTests provided 28 key measures. The data generally failed to show normal distributions (Shapiro-Wilk $W$ test, $p<.05$ ), and several measures were ordinal; therefore, the performance data, as well as the effect of demographic variables (age, sex, education) on performance, were analyzed using nonparametric techniques.

Construct validity. Construct validity of the cognitive tests was assessed using Spearman correlation analyses of the relationships between the subjects' performance on novel cognitive test measures and standard neuropsychological test measures. Construct validity was also assessed using multidimensional scaling, an alternative to factor analysis (Borg \& Groenen, 1997). The multidimensional scaling analysis was based on a correlation matrix including (1) correlations between novel cognitive test measures and standard neuropsychological test measures, (2) correlations among novel cognitive test measures, and (3) correlations among standard neuropsychological test measures. Multidimensional scaling graphically represents correlations between test measures by expressing these as relative euclidean distances, so that similar measures (those with high correlation coefficients) cluster close together and dissimilar measures are farther apart. It uses a function minimization algorithm that assesses different configurations to maximize goodness-of-fit (StatSoft, 2003), and the degree to which the distances on the map are discrepant from the values from the Spearman correlation matrix is referred to as the stress of the model. Higher stress values indicate greater discrepan- 
A

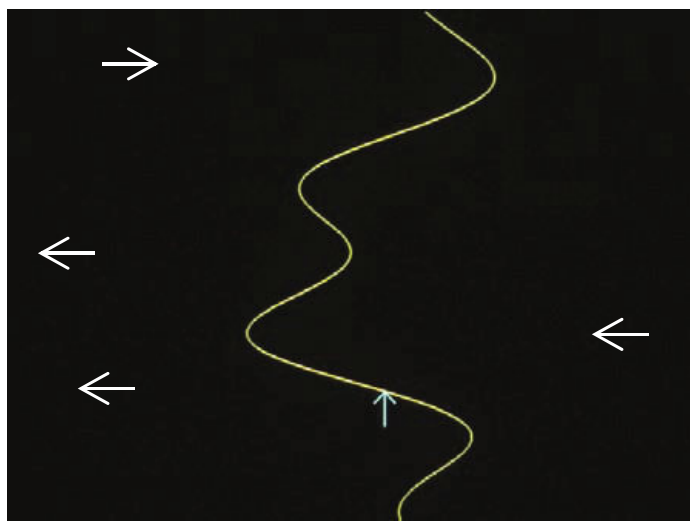

C

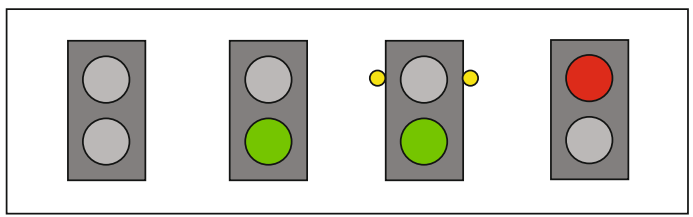

D

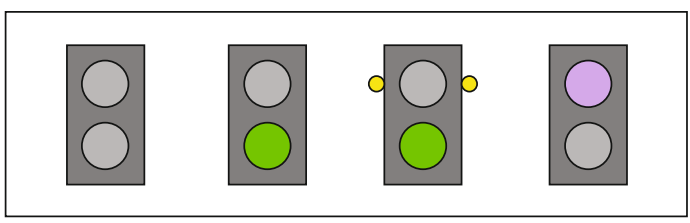

$\mathbf{F}$

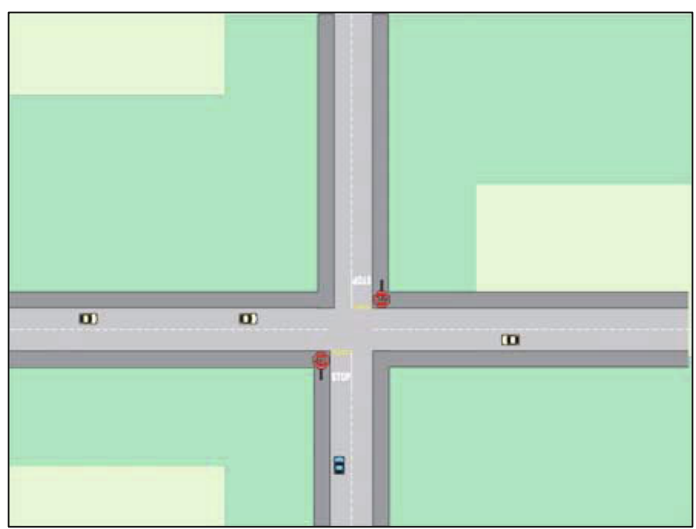

B

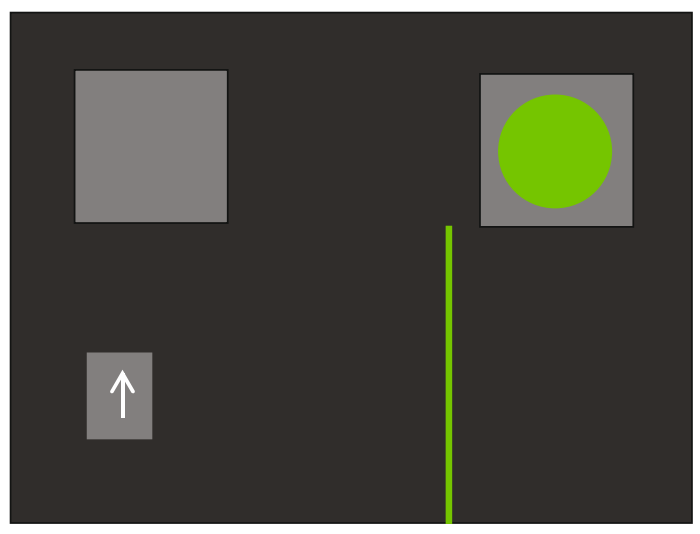

E

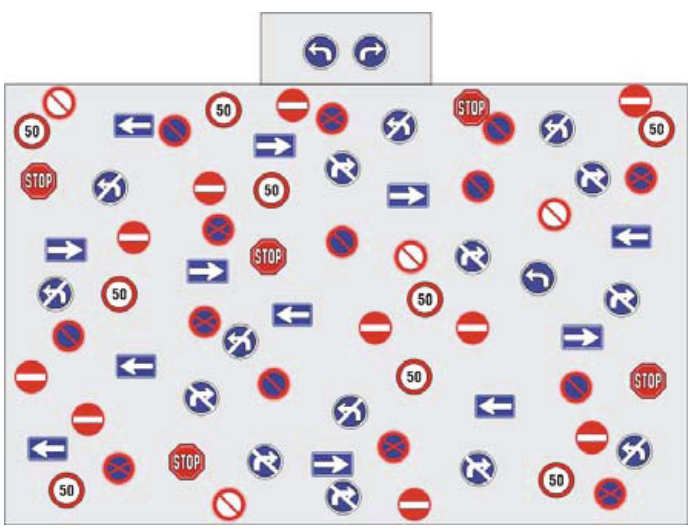

G

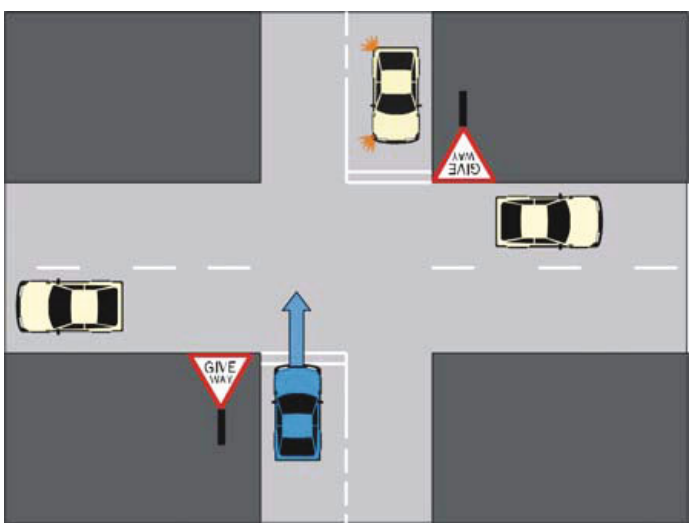

Figure 1. Sample screens from SMCTests. (A) Divided Attention: Subjects must respond verbally on whether or not the four horizontal arrows are all pointing in the same direction, while maintaining accurate tracking of the curve with the tip of the vertical arrow. (B) Complex Attention: Using the steering wheel, subjects must move the arrow from the gray box past the green line as quickly as possible when the green light changes from the left box to the right box. (C) Impulse Control: Four consecutive screens of a standard stimulus trial in which subjects must release the accelerator and press the brake as quickly as possible when the red light is presented. (D) Impulse Control: Four consecutive screens of a false stimulus trial in which subjects must suppress any impulse to release the accelerator when the purple light is presented. (E) Visual Search: Within the large box of 70 stimuli, subjects must locate 1 of the 2 invariant target stimuli shown in the top box. In this case, the turn-left arrow is presented, and the subject should turn the steering wheel toward the left as quickly as possible. (F) Planning: Subjects must drive the blue car down a road and across intersections while avoiding hazards and other vehicles. (G) Decision-Making: Subjects must decide as quickly as possible whether it is necessary to yield to any other car. In this case, the blue car does not need to yield to any other vehicles, and the subject should press the accelerator. 
Table 1

Spearman Rank-Order Correlations Between SMCTests Measures and Standard Neuropsychological Test Measures

\begin{tabular}{|c|c|c|c|c|c|c|c|c|c|}
\hline \multirow[b]{4}{*}{ SMCTests Measure } & \multicolumn{9}{|c|}{ Standard Neuropsychological Test Measure } \\
\hline & \multirow{2}{*}{\multicolumn{2}{|c|}{ CCPT }} & \multicolumn{6}{|c|}{ TEA } & \multirow{3}{*}{$\begin{array}{l}\text { Tower } \\
\text { of } \\
\text { Hanoi }\end{array}$} \\
\hline & & & \multirow[b]{2}{*}{ Tones $^{\mathrm{a}}$} & \multirow{2}{*}{$\begin{array}{c}\text { Tones } \\
\text { With } \\
\text { Distraction }\end{array}$} & \multirow{2}{*}{$\begin{array}{l}\text { Map } \\
\text { Search }^{\mathrm{b}}\end{array}$} & \multirow{2}{*}{$\begin{array}{l}\text { Telephone } \\
\text { Search }\end{array}$} & \multirow{2}{*}{$\begin{array}{l}\text { Dual } \\
\text { Task }^{\mathrm{c}}\end{array}$} & \multirow{2}{*}{$\begin{array}{c}\text { Dual Task } \\
\text { With } \\
\text { Decrement }\end{array}$} & \\
\hline & Omissions & Commissions & & & & & & & \\
\hline \multicolumn{10}{|l|}{ Complex Attention } \\
\hline Reaction and movement time & $.43^{* * *}$ & .00 & $-.27^{*}$ & -.20 & $-.34^{* *}$ & $.50^{* * *}$ & $.50^{* * *}$ & .01 & -.20 \\
\hline Number of lapses & $.49^{* * *}$ & .09 & -.23 & -.05 & -.24 & .11 & $.31^{*}$ & $.34^{* *}$ & -.25 \\
\hline \multicolumn{10}{|l|}{ Impulse Controld } \\
\hline Number of commissions & .21 & $.50^{* * *}$ & -.03 & .15 & .01 & -.09 & -.06 & .01 & -.05 \\
\hline \multicolumn{10}{|l|}{ Visual Search } \\
\hline Mean response time & $.26^{*}$ & .04 & .00 & -.17 & $-.50^{* * *}$ & $.59^{* * *}$ & $.52^{* * *}$ & .09 & $-.32^{*}$ \\
\hline Correct responses & -.20 & -.08 & .03 & $.31^{*}$ & $.57^{* * *}$ & $-.45^{* * *}$ & $-.54^{* * *}$ & $-.30^{*}$ & -.11 \\
\hline \multicolumn{10}{|l|}{ Divided Attention } \\
\hline $\begin{array}{l}\text { Dual-task random } \\
\text { tracking error }\end{array}$ & $.28^{*}$ & .04 & .07 & -.24 & $-.47^{* * *}$ & $.48^{* * *}$ & $.42^{* *}$ & -.04 & -.13 \\
\hline Dual-task correct responses & -.24 & -.16 & $.30^{*}$ & $.29^{*}$ & .12 & -.22 & $-.26^{*}$ & -.24 & .20 \\
\hline \multicolumn{10}{|l|}{ Planning } \\
\hline Total distance traveled & -.10 & .01 & .05 & .06 & $.48^{* * *}$ & $-.35^{* *}$ & $-.40^{* *}$ & .00 & .24 \\
\hline $\begin{array}{l}\text { Duration of lateral } \\
\text { position errors }\end{array}$ & .25 & .01 & -.21 & -.23 & $-.29^{*}$ & $-.27^{*}$ & $.37^{* *}$ & .12 & $-.39^{* *}$ \\
\hline Number of hazards hit & $.31^{*}$ & .10 & -.16 & .05 & -.15 & .13 & .13 & -.14 & -.25 \\
\hline Number of crashes & .23 & -.02 & $-.28^{*}$ & -.12 & $-.26^{*}$ & $.34^{* *}$ & $.37^{* *}$ & -.07 & -.22 \\
\hline \multicolumn{10}{|l|}{ Decision-Making } \\
\hline Mean response time & $.34^{* *}$ & -.02 & -.25 & $-.44^{* * *}$ & $-.46^{* * *}$ & $.44^{* * *}$ & $.48^{* * *}$ & .17 & $-.30^{*}$ \\
\hline Correct responses & $-.36^{* *}$ & -.25 & .24 & $.35^{* *}$ & $.41^{* *}$ & $-.52^{* * *}$ & $-.57^{* * *}$ & -.21 & $.39^{* *}$ \\
\hline
\end{tabular}

cies between the relative distances and the input correlation matrix, whereas lower stress values indicate a better fit. A rule of thumb is that a stress measure of under 0.1 is good; anything over 0.15 is considered unacceptable (Young, 1985). Measures expected to be similar to each other were planning, in terms of the Planning number of hazards hit and the tower of Hanoi total achievement score; sustained attention, in terms of the Complex Attention number of lapses and the Conners' Continuous Performance Test omissions; impulsivity, in terms of the Impulse Control commissions and the Conners' Continuous Performance Test commissions; visual search, in terms of the Visual Search number of correct responses and the Test of Everyday Attention map search number of items circled; and divided attention, in terms of the Divided Attention random tracking error and the Test of Everyday Attention dual-task time per target. The Decision-Making number of correct responses was also included in the analysis, although it was not expected a priori to correlate with any standard neuropsychological test measure.

Face validity. In order to investigate the face validity of SMCTests, subjects were asked to answer two questions at the end of the off-road assessment: (1) Which of the tests that you did today do you think would be most useful if it was used to try and predict your ability to drive? and (2) Which test do you think would be the least useful if it was used to try and predict your ability to drive?

Each subject was asked to rank up to three tests in answer to each question. For each subject, tests were given a score of 3 (most useful), 2 (second most useful), 1 (third most useful), 0 (neither most useful nor least useful), -1 (third least useful), -2 (second least useful), or -3 (least useful). A mean score was then calculated for each test. It was hypothesized that the tests that subjects would identify as being most predictive of on-road driving would reflect the degree of face validity, with respect to on-road driving.

On-road assessment. A subset of 12 subjects ( 2 females and 2 males from each of the three age groups) was selected to represent a cross-section of relatively good, average, or poorer off-road test performance. These 12 subjects undertook a 60 -min on-road driving assessment under the supervision of an independent driving instructor and an occupational therapist, both of whom were blinded to offroad test performance. The on-road assessment used a standard test route and included single-lane roundabouts, dual-lane roundabouts, dual-lane roads, controlled intersections (yield sign, stop sign, or traffic light), uncontrolled intersections, and changes in speed zone (i.e., $50-\mathrm{km} / \mathrm{h}, 60-\mathrm{km} / \mathrm{h}$, and $80-\mathrm{km} / \mathrm{h}$ sections). The assessments were approximately $45 \mathrm{~min}$ in duration. On-road driving performance was scored as a pass or a fail using the Advanced Driving Assessment System, the standard system used by all driving assessment occupational therapists in New Zealand. Performance was scored in terms of search, hazard identification, controls, and observation of traffic regulations. On-road performance was also rated on a $0-10$ driving scale (for a description, see Innes et al., 2007). Spearman correlation analysis was used to determine the relationship between off-road test performance and on-road driving score.

Test-retest stability and reliability. A second subset of 12 subjects ( 2 females and 2 males from each of the three age groups) was selected to represent a cross-section of relatively good, average, or poorer off-road test performance. These subjects carried out a repeat of SMCTests 6 to 9 months after their first test session in order to determine the test-retest stability and reliability of these tests. Testretest stability was assessed using the Wilcoxon matched-pairs test to identify any significant differences in subjects' performance on 28 key SMCTests measures between Session 1 and Session 2. Intraclass correlations were calculated for the key measures between the first and second sessions in order to provide an estimate of reliability or consistency of values within cases.

\section{RESULTS}

Each of the key SMCTests cognitive measures correlated with at least one measure derived from the standard neuropsychological tests (Table 1). The strongest correlations were 


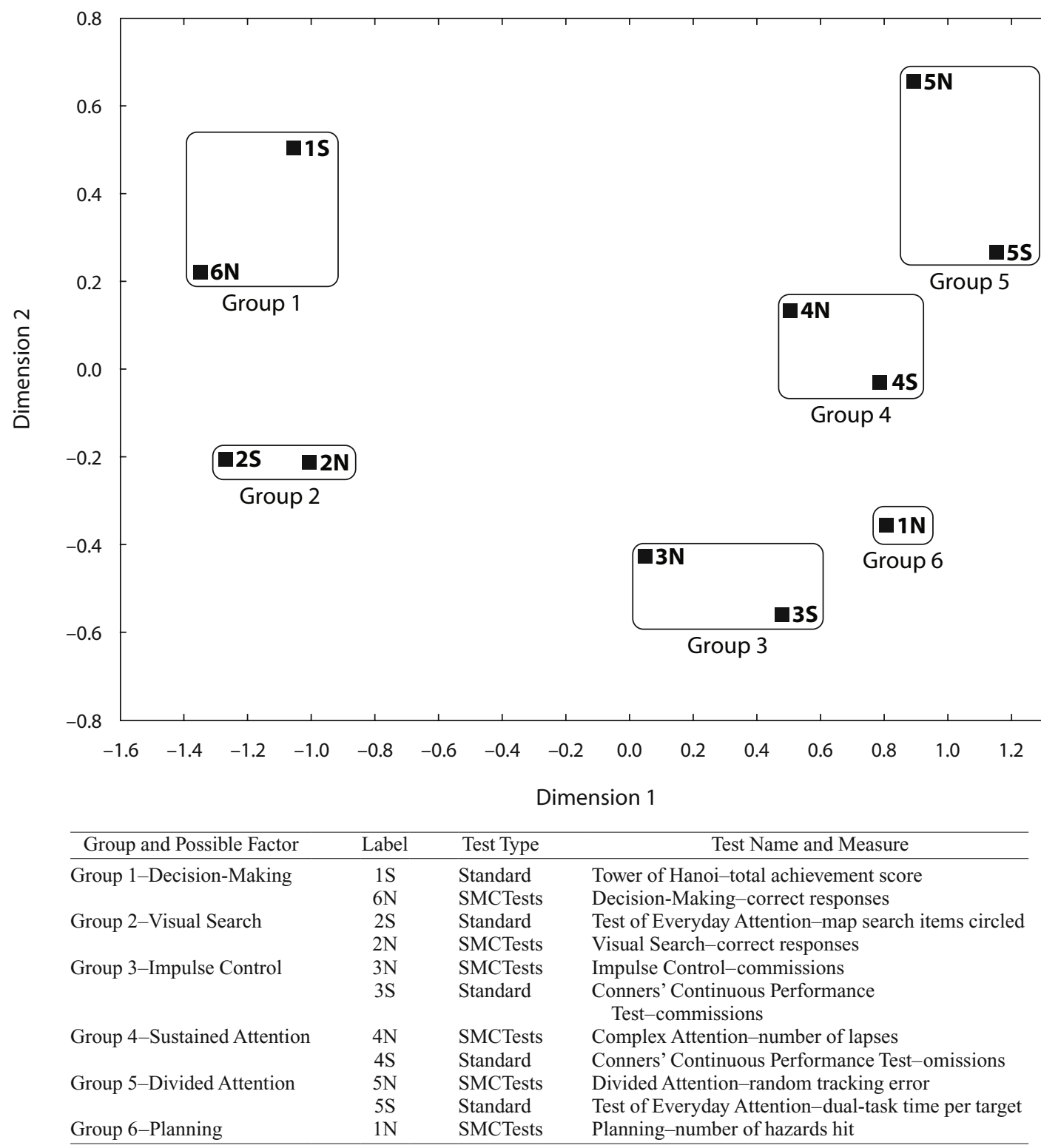

Figure 2. Representation of similarities (distances) between novel cognitive test measures (those labeled " $N$ ") and standard neuropsychological test measures (those labeled "S"), using multidimensional scaling. Measures expected to assess similar functions were placed closed together and given the same number. Those with high correlation coefficients cluster together and dissimilar measures are placed farther apart. Visual Search number correct (2N) and everyday attention map search items (circled 2S) formed Group 2; Impulse Control commissions (3N) and Conners' Continuous Performance Test commissions (3S) formed Group 3; Complex Attention number of lapses (4N) and Conners' Continuous Performance Test omissions (4S) formed Group 4; and Divided Attention random tracking error (5N) and everyday attention dual-task time per target (5S) formed Group 5. However, against expectation, planning number of hazards hit (1N) did not show any similarity with Tower of Hanoi total achievement score (1S). Tower of Hanoi total achievement score (1S) was most closely aligned with Decision-Making correct responses (6N), forming Group 1. Planning number of hazards hit (1N) was placed between Group 3 (impulsivity) and Group 4 (sustained attention).

between the visual search measures and the Test of Everyday Attention telephone search $\left(r_{\mathrm{s}}=.59\right)$ and map search $\left(r_{\mathrm{s}}=\right.$ .57) subtests and between the decision making measures and the everyday attention dual-task subtest $\left(r_{\mathrm{s}}=.57\right)$.

Correlations between measures from the SMCTests and from the standard neuropsychological tests that were expected to assess similar cognitive functions were used to form a correlation matrix and were analyzed using multidi- mensional scaling. The multidimensional scaling analysis produced a 2-D model with a low stress value $(0.078)$, indicating a good fit between the multidimensional-scaling, relative-distance map and the input correlation matrix. Similarities (relative distances) between test measures are provided in Figure 2.

Face validity analysis showed that subjects believed that the novel cognitive tests would be more useful for predict- 


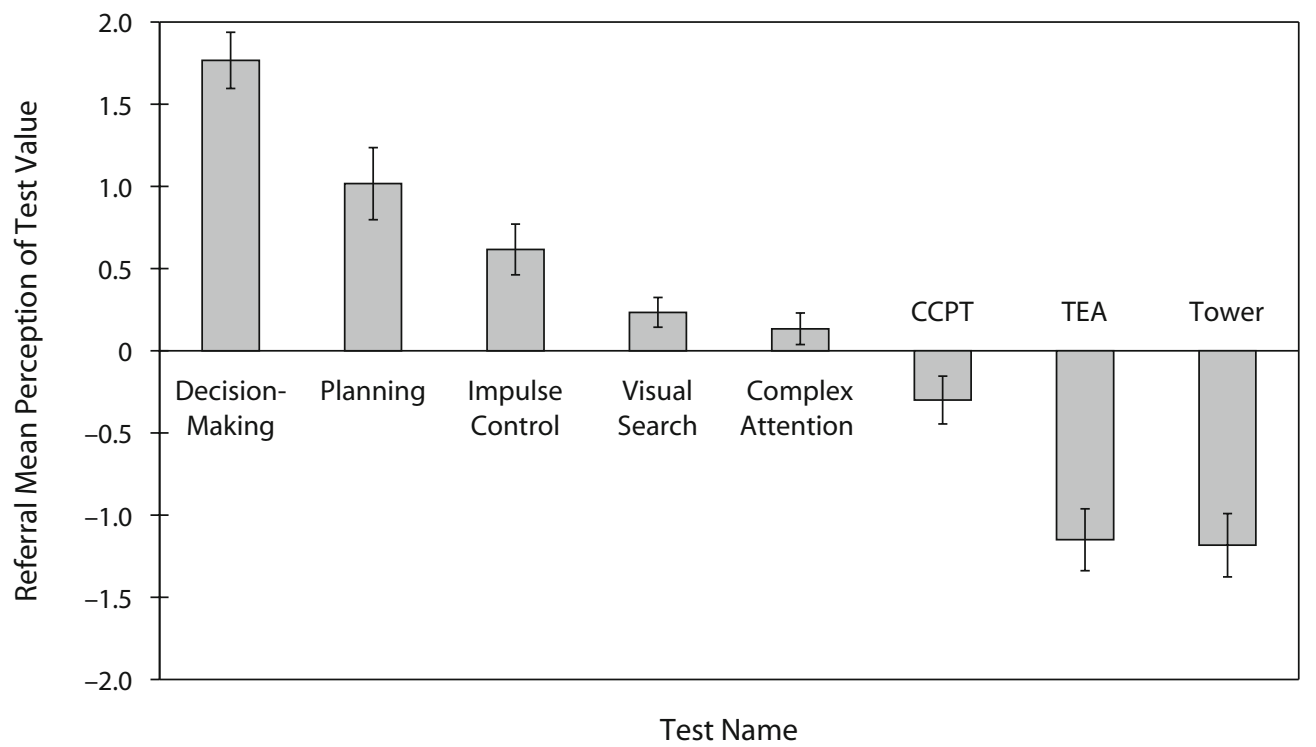

Figure 3. Histograms of subject opinions on the perceived usefulness of the various tests. Tests considered to be the most useful as predictors of on-road driving ability are shown as positive values. Tests considered to be the least useful as predictors of on-road driving ability are shown as negative values. CCPT, Conners' Continuous Performance Test; TEA, Test of Everyday Attention; Tower, Tower of Hanoi.

ing on-road driving ability than would the standard neuropsychological cognitive tests (Figure 3). Specifically, subjects felt that the novel cognitive tests of DecisionMaking and Planning would be most predictive of on-road driving ability. Conversely, the standard neuropsychological tests Tower of Hanoi and Test of Everyday Attention were subjectively regarded as least useful.

Wilcoxon matched pairs analysis indicated no difference in performance between the two sessions on 26 of 28 key SMCTests measures, the exceptions being Sine Tracking and Divided Attention Random Tracking (Table 2). Intraclass correlation analysis showed that the majority of key SMCTests measures (23 of 28) had significant reliability scores, indicating consistent performance by subjects on these measures across the two test sessions. Measures with nonsignificant reliability coefficients are shown in Table 2.

All 12 subjects who undertook an on-road assessment received "pass" driving scores (range $=6-9$ ). A relationship between on-road driving and SMCTests performance was found, with significant Spearman correlations between driving scores and ballistic movement peak velocity $\left(r_{\mathrm{s}}=\right.$ $.80)$, and between mean reaction and movement time measures from footbrake reaction $\left(r_{\mathrm{s}}=.75\right)$, hand control reaction $\left(r_{\mathrm{s}}=-.66\right)$, and complex attention $\left(r_{\mathrm{s}}=-.62\right)$.

Age detrimentally affected performance on most SMCTests measures, with generally moderate correlations between age and performance $\left(r_{\mathrm{s}}=.28\right.$ to .65) (Table 3$)$. Table 3 also provides SMCTests medians for the three age groups, as well as Mann-Whitney $U$ analysis of the differences in SMCTests performance among the three age groups. Overall, correlations between age and performance were stronger for the novel cognitive tests than were those for the sensory-motor tests. Correlations were strongest for measures of speed and reaction time on tests of visual search, complex attention, and decision making. Age did not affect performance on non-speed-dependent measures of accuracy, response inhibition, visual resolution, or static perception. No subject in any of the three age groups had difficulty understanding or remembering the test instructions or undertaking the test procedures. After controlling for age, years of education was not significantly correlated with performance on any SMCTests measures.

On average, males had higher upper-limb peak velocities, had faster lower-limb reaction and movement times, had more accurate visuomotor tracking, drove farther, and had fewer crashes with other vehicles in planning (Table 4). This is in keeping with previous studies (Boucher, Denis, \& Landriault, 1991; Halpern, 1997; Jones et al., 1986; Lewis, Kamon, \& Hodgson, 1986), indicating better performance in males on tests of strength, acceleration, visuomotor coordination, and visuospatial and spatiotemporal functions.

\section{DISCUSSION}

To meet the worldwide demand for specialized driving assessment, an accurate and comprehensive standardized off-road assessment procedure is required. We propose a novel battery of driving-related sensory-motor and cognitive tests-SMCTests- which has shown good face validity, stability, reliability, and construct validity in normal subjects. SMCTests has also previously been used to model on-road driving ability in drivers with brain disorders, with a classification accuracy for pass or fail of 94\% (Innes et al., 2007), which compares well with classification accuracies of $70 \%-94 \%$ in other test batteries (Brown et al., 2005; Fox, Bowden, Bashford, \& Smith, 
Table 2

Test-Retest Stability and Reliability of SMCTests Measures

\begin{tabular}{|c|c|c|c|c|c|}
\hline \multirow[b]{2}{*}{ SMCTests Measure } & \multicolumn{2}{|c|}{ Median } & \multirow{2}{*}{$\begin{array}{c}\text { Wilcoxon } \\
\text { Matched Pairs } \\
\text { Test } p \text { Level }\end{array}$} & \multirow{2}{*}{$\begin{array}{c}\text { Intraclass } \\
\text { Correlation } \\
\text { Reliability } \\
\text { Coefficient } \alpha\end{array}$} & \multirow{2}{*}{$\begin{array}{c}\text { Intraclass } \\
\text { Correlation } \\
p \text { Level }\end{array}$} \\
\hline & Session 1 & Session 2 & & & \\
\hline \multicolumn{6}{|c|}{ Sensory-Motor Tests } \\
\hline Visual Resolution (resolution, in mm) & 0.47 & 0.47 & 1.00 & .916 & .00 \\
\hline Static Perception (resolution, in mm) & 1.17 & 1.13 & .29 & .996 & .00 \\
\hline Dynamic Perception (resolution, in mm) & 1.36 & 1.36 & .11 & .883 & .00 \\
\hline Footbrake (mean reaction and movement time, in msec) & 660 & 628 & .51 & .822 & .01 \\
\hline Footbrake and Clutch (mean reaction and movement time, in msec) & 788 & 691 & .07 & .953 & .00 \\
\hline Hand Control (mean reaction and movement time, in msec) & 366 & 366 & .85 & .706 & .03 \\
\hline Ballistic Movement (best reaction time, in msec) & 297 & 300 & .81 & .585 & $.08^{\mathrm{a}}$ \\
\hline Ballistic Movement (peak velocity, in $\mathrm{mm} / \mathrm{sec}$ ) & 1,184 & 1,326 & .06 & .916 & .00 \\
\hline Step Tracking (mean absolute error, in mm) & 13.58 & 13.01 & .18 & .876 & .00 \\
\hline Sine Tracking (Run 1 mean absolute error, in mm) & 11.46 & 11.69 & .75 & .238 & $.33^{\mathrm{a}}$ \\
\hline Sine Tracking (Run 2 mean absolute error, in mm) & 7.86 & 7.02 & $.02^{\mathrm{b}}$ & .831 & .00 \\
\hline Random Tracking (Run 1 mean absolute error, in mm) & 7.34 & 6.71 & .59 & .802 & .01 \\
\hline Random Tracking (Run 2 mean absolute error, in mm) & 6.11 & 5.20 & .08 & .721 & .02 \\
\hline Arrows Perception (no. correct) & 12 & 12 & 1.00 & .868 & .00 \\
\hline \multicolumn{6}{|c|}{ Cognitive Tests } \\
\hline Complex Attention (mean reaction and movement time, in msec) & 668 & 724 & .64 & .929 & .00 \\
\hline Complex Attention (no. lapses) & 0 & 0 & .23 & -.200 & $.62^{\mathrm{a}}$ \\
\hline Impulse Control (mean reaction and movement time, in msec) & 911 & 1,020 & .94 & .883 & .00 \\
\hline Impulse Control (no. commissions) & 2.50 & 2 & .24 & .772 & .01 \\
\hline Visual Search (response time, in sec) & 4.30 & 4.40 & .48 & .843 & .00 \\
\hline Visual Search (no. correct) & 18.50 & 17 & .76 & .571 & $.09^{\mathrm{a}}$ \\
\hline Divided Attention (Random Tracking mean absolute error, in mm) & 7.89 & 6.93 & $.04^{b}$ & .660 & .04 \\
\hline Divided Attention (no. correct, arrow perception) & 12 & 12 & .35 & .447 & $.17^{\mathrm{a}}$ \\
\hline Planning (distance traveled, in $\mathrm{m}$ ) & 3.80 & 3.80 & .22 & .831 & .00 \\
\hline Planning (duration of lateral position errors, in sec) & 4.40 & 4.80 & .16 & .652 & .04 \\
\hline Planning (no. hazards hit) & 2 & 2 & 1.00 & .809 & .01 \\
\hline Planning (no. crashes) & 0.50 & 0 & .07 & .950 & .00 \\
\hline Decision-Making (mean reaction time, in sec) & 4.20 & 4.10 & .67 & .917 & .00 \\
\hline Decision-Making (no. correct) & 22.50 & 24 & .16 & .700 & .03 \\
\hline
\end{tabular}

aNonreliable measure between Session 1 and Session 2. bNonstable measure between Session 1 and Session 2.

1997; Galski et al., 1993; Lundqvist, Gerdle, \& Rönnberg, 2000; Mazer et al., 1998; McKenna, Jefferies, Dobson, \& Frude, 2004; Myers, Ball, Kalina, Roth, \& Goode, 2000; Nouri, Tinson, \& Lincoln, 1987).

A limitation of our study was the relatively small sample size of 60 healthy subjects. Although nonparametric analyses are the most powerful methods to use with nonnormally distributed data, especially with a small sample size (Bridge \& Sawilowsky, 1999), a larger sample size would allow greater freedom to utilize parametric analyses.

Overall, the correlational and multidimensional scaling analyses confirmed that four of the six novel cognitive tests (Impulse Control, Visual Search, Complex Attention, Divided Attention) had a moderately strong similarity to standard cognitive tests designed to assess similar cognitive functions. However, contrary to expectations, multidimensional scaling analysis revealed that Planning was not similar to the Tower of Hanoi subtest. Negotiating hazards and maintaining road position in Planning requires the integration of a number of cognitive functions for satisfactory performance, including aspects of planning and visuospatial organization. Thus, it was expected that this measure would show some similarity to performance on the Tower of Hanoi subtest, as it has been described as assessing planning and visuospatial problem solving (Delis,
Kaplan, \& Kramer, 2001b; Homack, Lee, \& Riccio, 2005; Lezak, 1995). The dissimilarity between measures from the two tests suggests either that other cognitive functions are more important for performance in planning, or that the planning component of the Tower of Hanoi subtest is not as prominent as has been proposed in the literature. Planning number of hazards hit had some similarity with measures of impulsivity and sustained attention. The relative complexity of planning is likely to be an advantage in detecting different and subtle deficits, at the same time making it more difficult to identify which deficits underpin poor performance. There was no test measure with which DecisionMaking was expected a priori to be correlated. However, in contrast to Planning, Decision-Making was similar to the Tower of Hanoi subtest. Because Decision-Making does not appear to have any planning component, this result presumably emphasizes the shared visuospatial problemsolving and decision-making aspects of Decision-Making and Tower of Hanoi performance.

So why not just use a set of standard neuropsychological tests to assess driving-related cognitive functions? There are a number of advantages that a specifically designed battery of tests of cognitive functions can confer for determining safe on-road driving: (1) using face validity hardware and software, so possible referrals can see how their deficits 
Table 3

SMCTests Measures and the Effect of Age on Performance

\begin{tabular}{|c|c|c|c|c|c|}
\hline \multirow[b]{2}{*}{ SMCTests Measure } & \multicolumn{3}{|c|}{ Median } & \multirow[b]{2}{*}{$\begin{array}{c}\text { Correlation } \\
\text { With Age }\end{array}$} & \multirow{2}{*}{$\begin{array}{c}\text { Mann-Whitney } U \\
\text { Between } \\
\text { Age Groups }\end{array}$} \\
\hline & $\begin{array}{l}\text { Group } 1 \\
\text { (Young) }\end{array}$ & $\begin{array}{l}\text { Group } 2 \\
\text { (Middle) }\end{array}$ & $\begin{array}{c}\text { Group } 3 \\
\text { (Older) }\end{array}$ & & \\
\hline \multicolumn{6}{|c|}{ Sensory-Motor Tests } \\
\hline Footbrake (mean reaction and movement time, in msec) & 581 & 575 & 648 & $.28^{*}$ & $1>3$ \\
\hline Footbrake and Clutch (mean reaction and movement time, in msec) & 645 & 693 & 779 & $.30^{*}$ & n.s. \\
\hline Hand Control (mean reaction and movement time, in msec) & 351 & 344 & 377 & $.44^{*}$ & 1 and $2>3$ \\
\hline Visual Resolution (resolution, in mm) & 0.18 & 0.18 & 0.18 & .04 & n.s. \\
\hline Static Perception (resolution, in $\mathrm{mm}$ ) & 0.45 & 0.45 & 0.45 & -.10 & n.s. \\
\hline Dynamic Perception (resolution, in mm) & 0.54 & 0.54 & 0.54 & $.34^{*}$ & $1>3$ \\
\hline Ballistic Movement (best reaction time, in msec) & 291 & 297 & 311 & $.34^{*}$ & $1>3$ \\
\hline Ballistic Movement (peak velocity, in $\mathrm{mm} / \mathrm{sec}$ ) & 1,410 & 1,171 & 1,071 & $-.47^{*}$ & $1>2$ and 3 \\
\hline Step Tracking (mean absolute error, in $\mathrm{mm}$ ) & 12.50 & 14.20 & 13.90 & $.44^{*}$ & $1>2$ and 3 \\
\hline Sine Tracking (Run 1 mean absolute error, in $\mathrm{mm}$ ) & 11.20 & 12.60 & 14.20 & $.43^{*}$ & $1>2$ and 3 \\
\hline Sine Tracking (Run 2 mean absolute error, in mm) & 6.70 & 8.20 & 8.60 & $.39^{*}$ & $1>3$ \\
\hline Random Tracking (Run 2 mean absolute error, in mm) & 5 & 5.60 & 6.50 & $.37^{*}$ & $1>3$ \\
\hline Random Tracking (Run 1 mean absolute error, in mm) & 6.40 & 7.10 & 7.30 & $.36^{*}$ & $1>2$ and 3 \\
\hline Arrows Perception (no. correct) & 12 & 12 & 12 & .13 & n.s. \\
\hline \multicolumn{6}{|c|}{ Cognitive Tests } \\
\hline Complex Attention (mean reaction and movement time, in msec) & 668 & 800 & 894 & $.64^{*}$ & $1>2>3$ \\
\hline Complex Attention (no. lapses) & 1 & 2 & 1.50 & .19 & n.s. \\
\hline Impulse Control (no. omissions) & 0 & 0 & 0 & .13 & n.s. \\
\hline Impulse Control (no. commissions) & 2 & 2.50 & 3 & .00 & n.s. \\
\hline Visual Search (mean response time, in sec) & 3.40 & 4.30 & 4.50 & $.65^{*}$ & $1>2$ and 3 \\
\hline Visual Search (no. correct) & 20 & 18.50 & 17 & $-.55^{*}$ & $1>3$ \\
\hline Divided Attention (Random Tracking mean absolute error, in $\mathrm{mm}$ ) & 6.70 & 8 & 8.40 & $.44^{*}$ & $1>2$ and 3 \\
\hline Divided Attention (no. correct) & 12 & 12 & 12 & -.11 & n.s. \\
\hline Planning (distance traveled, in m) & 4 & 3.80 & 3.80 & $-.50^{*}$ & $1>2$ and 3 \\
\hline Planning (duration of lateral position errors, in sec) & 1.20 & 5.50 & 7.10 & $.50^{*}$ & $1>2$ and 3 \\
\hline Planning (no. hazards hit) & 2 & 2 & 2.50 & .22 & $1>3$ \\
\hline Planning (no. crashes) & 0 & 0 & 1 & $.43^{*}$ & $1>3$ \\
\hline Decision-Making (mean response time, in sec) & 3.20 & 4 & 4.50 & $.54^{*}$ & $1>2$ and 3 \\
\hline Decision-Making (no. correct) & 24.50 & 24 & 22 & $-.50^{*}$ & 1 and $2>3$ \\
\hline
\end{tabular}

Note-A higher Mann-Whitney $U$ score is equivalent to a "better" score for some test measures and a "worse" score for the other test measures. However, for the results of the Mann-Whitney $U$ analysis of the difference in performance between the three age groups, " $>$ " is equivalent to "better" performance. The result " $1>3$ " indicates that Group 1 performance was better than Group 3 performance, but that Group 2 performance was not different from that for Group 1 or Group $3 .{ }^{*} p<.05$.

may affect the safety of their on-road driving; (2) increasing the ease and speed of administration for the assessor and referral through computerization of tests, in turn releasing the assessor from having to record times and errors, as is necessary in some pen-and-paper tests; (3) decreasing the risk of assessor input error; (4) providing the assessor with more time to observe, for a more qualitative appraisal of a referral's performance; (5) automating analysis of performance; and (6) being able to design hardware and software with a contextual human interface, so referrals who are computer illiterate and/or computer phobic can undertake the tests with as little stress as possible.
The use of car images, road signs, symbols (such as traffic lights), and contextual apparatus (i.e., car body, steering wheel, pedals) to maximize the face validity of the novel cognitive tests was intentional. Face validity analysis confirmed that the apparatus and symbols were successful in increasing the subjective face validity of the tests in the opinion of our healthy subjects, who believed that the novel cognitive tests would give a better indication of on-road driving ability than would the standard neuropsychological tests. Subjects considered Decision-Making to be the test most likely to predict their on-road driving ability, with Planning being second. Since these were the

Table 4

Effect of Sex on Performance of SMCTests: Measures With a Difference Between Males and Females

\begin{tabular}{|c|c|c|c|c|}
\hline \multirow[b]{2}{*}{ SMCTests Measure } & \multicolumn{2}{|c|}{ Median } & \multirow{2}{*}{$\begin{array}{c}\text { Mann-Whitney } U \\
p \text { Level }\end{array}$} & \multirow{2}{*}{$\begin{array}{l}\text { Cohen-Type } \\
\text { Effect Size }\end{array}$} \\
\hline & Females & Males & & \\
\hline Ballistic Movement (peak velocity, in mm/sec) & 1,114 & 1,297 & .002 & 0.83 \\
\hline Sine Tracking (Run 2 mean absolute error, in mm) & 9.2 & 7.3 & .007 & 0.73 \\
\hline Random Tracking (Run 2 mean absolute error, in mm) & 6.4 & 5.2 & .012 & 0.68 \\
\hline Planning (no. crashes) & 1 & 0 & .032 & 0.63 \\
\hline Footbrake Reaction (mean reaction and movement time, in msec) & 663 & 583 & .024 & 0.62 \\
\hline Planning (distance traveled, in $\mathrm{m}$ ) & 3.8 & 3.9 & .031 & 0.58 \\
\hline Footbrake and Clutch (mean reaction and movement time, in msec) & 801 & 685 & .044 & 0.55 \\
\hline
\end{tabular}


only two tests in the battery that specifically showed vehicles interacting with other vehicles on simulated roads and intersections, it is perhaps not surprising that the subjects most associated their performance on these tests with their on-road driving ability. It is hoped that face validity tests will provide failed or borderline subjects useful information about their deficits and about potential consequences of their deficits during driving and, thus, will obtain as high a level as possible of acceptance of, and compliance with, assessment recommendations.

Overall, SMCTests measures proved to be stable and reliable across the two test sessions. However, two measures of visuomotor accuracy (Sine Tracking and Divided Attention Random Tracking) had 10\% to $16 \%$ decreases in mean error, reflecting a practice effect that would need to be taken into account in repeat assessments. Both Divided Attention number of correct responses and Complex Attention number of lapses were found to be unreliable across the two sessions. However, errors on both measures had a relatively low rate of occurrence, showing a ceiling effect in normal subjects. The reliability of these measures across sessions may need to be assessed in a group that shows a greater number of errors, such as people with brain disorders. Mean absolute error from the first run of sine tracking was also unreliable between Sessions 1 and 2 . This may have been due to the relatively steep learning curve with sine tracking. Performance during the first run gave an indication of how quickly subjects can adapt to the novel task. Performance on subsequent runs of sine tracking gives an indication of how much improvement subjects can make with further practice. Speed of adaptation within the first run of sine tracking and improvement with practice across runs provide useful information about an individual; but because these can vary greatly, there could be an inconsistent measure between subjects.

Significant correlations were observed between driving scores and performance on four SMCTests measures. These results are consistent with there being a relationship between off- and on-road performance, even though - with a subset of only 12 subjects being assessed on-road - correlations needed to be relatively strong $\left(r_{\mathrm{s}}>\right.$ $.62)$ to reach significance $(p<.05)$. Test measures correlated with on-road driving scores were much more of a sensory-motor than of a higher cognitive nature. This seems appropriate in a group of healthy adults having no indication of cognitive impairment.

SMCTests is currently undergoing trials as the off-road assessment tool in three occupational therapy centers. Although the battery is not yet commercially available, commercialization of it and of the associated apparatus is being actively pursued through the Canterbury District Health Board.

During a 14-month survey, $68 \%$ of DAVAS referrals with known or suspected brain lesions failed an on-road driving assessment due to definite safety concerns. Clearly, there was a substantial risk of an accident during these on-road assessments. Confirmation of the stability, reliability, and validity of SMCTests measures provides us with greater certainty of being able to reliably detect and identify deficits related to unsafe driving and increased risk of accidents.

\section{AUTHOR NOTE}

This work was supported through grants from the Foundation for Research, Science, and Technology; the Accident Compensation Corporation; and the University of Otago. We thank Paul Barrett and Christopher Frampton for their statistical advice. Correspondence concerning this article should be addressed to C. R. H. Innes, Van der Veer Institute for Parkinson's and Brain Research, 66 Stewart St., Christchurch 8011, New Zealand (e-mail: carrie.innes@vanderveer.org.nz).

\section{REFERENCES}

Austroads (2006). Assessing fitness to drive for commercial and private vehicle drivers (3rd ed.). Sydney, Australia: Author.

Berger, J. T., Rosner, F., Kark, P., \& Bennett, A. J. (2000). Reporting by physicians of impaired drivers and potentially impaired drivers. Journal of General Internal Medicine, 15, 667-672.

Borg, I., \& Groenen, P. (1997). Modern multidimensional scaling. Theory and applications. New York: Springer.

Boucher, J.-L., Denis, S., \& Landriault, J.-A. (1991). Sex differences and effects of aging on visuomotor coordination. Perceptual \& Motor Skills, 72, 507-512.

BRIDGE, P. D., \& SAwILOwsKy, S. S. (1999). Increasing physicians' awareness of the impact of statistics on research outcomes: Comparative power of the $t$-test and Wilcoxon Rank-Sum test in small samples applied research. Journal of Clinical Epidemiology, 52, 229-235.

Brown, L. B., Stern, R. A., CAhn-Weiner, D. A., Rogers, B., Messer, M. A., Lannon, M. C., ET AL. (2005). Driving Scenes test of the Neuropsychological Assessment Battery (NAB) and on-road driving performance in aging and very mild dementia. Archives of Clinical Neuropsychology, 20, 209-215.

Christchurch Neurotechnology Research Programme (2006). Canterbury Driving Assessment Tool (CanDAT) incorporating SMCTests version 5.0: User's manual. Christchurch, New Zealand: Author.

Conners, C. K. (1995). Conners' Continuous Performance Test. Toronto: Multi-Health Systems.

Dalrymple-Alford, J. C., Kalders, A. S., Jones, R. D., \& Watson, R. W. (1994). A central executive deficit in patients with Parkinson's disease. Journal of Neurology, Neurosurgery, \& Psychiatry, 57, 360-367.

Dalrymple-Alford, J. C., Kerr, P. A., \& Jones, R. D. (2003). The effects of alcohol on driving-related sensorimotor performance across four times of day. Journal of Studies on Alcohol, 64, 93-97.

Davidson, P. R., Jones, R. D., Andreae, J. H., \& Sirisena, H. R. (2002). Simulating closed- and open-loop voluntary movement: A nonlinear control-systems approach. IEEE Transactions on Biomedical Engineering, 49, 1242-1252.

Davidson, P. R., Jones, R. D., \& Peiris, M. T. R. (2007). EEG-based lapse detection with high temporal resolution. IEEE Transactions on Biomedical Engineering, 54, 832-839.

Davidson, P. R., Jones, R. D., Sirisena, H. R., \& Andreae, J. H (2000). Detection of adaptive inverse models in the human motor system. Human Movement Science, 19, 761-795.

Delis, D. C., Kaplan, E., \& Kramer, J. H. (2001a). Delis-Kaplan Executive Function System ( $D-K E F S$ ). San Antonio, TX: Psychological Corp.

Delis, D. C., Kaplan, E., \& Kramer, J. H. (2001b). Delis-Kaplan Executive Function System (D-KEFS) examiner's manual. San Antonio, TX: Psychological Corp.

Fox, G. K., Bowden, S. C., Bashford, G. M., \& Smith, D. S. (1997). Alzheimer's disease and driving: Prediction and assessment of driving performance. Journal of the American Geriatrics Society, 45, 949-953.

Galski, T., Bruno, R. L., \& Ehle, H. T. (1993). Prediction of behindthe-wheel driving performance in patients with cerebral brain damage: A discriminant function analysis. American Journal of Occupational Therapy, 47, 391-396.

HALPERN, D. F. (1997). Sex differences in intelligence: Implications for education. American Psychologist, 52, 1091-1102.

HaWLEY, C. A. (2001). Return to driving after head injury. Journal of Neurology, Neurosurgery, \& Psychiatry, 70, 761-766.

Heikkilä, V.-M., TurkKa, J., Korpelainen, J., Kallanranta, T., \& Summala, H. (1998). Decreased driving ability in people with Parkinson's disease. Journal of Neurology, Neurosurgery, \& Psychiatry, 64, 325-330. 
Heitger, M. H., Anderson, T. J., Jones, R. D., Dalrymple-Alford, J. C., Frampton, C. M., \& Ardagh, M. W. (2004). Eye movement and visuomotor arm movement deficits following mild closed head injury. Brain, 127, 575-590.

Heitger, M. H., Jones, R. D., Dalrymple-Alford, J. C., Frampton, C. M., Ardagh, M. W., \& Anderson, T. J. (2006). Motor deficits and recovery during the first year following mild closed head injury. Brain Injury, 20, 807-824.

Homack, S., Lee, D., \& Riccio, C. A. (2005). Test review: Delis-Kaplan Executive Function System. Journal of Clinical \& Experimental Neuropsychology, 27, 599-609.

Hunt, L., Morris, J. C., Edwards, D., \& Wilson, B. S. (1993). Driving performance in persons with mild senile dementia of the Alzheimer type. Journal of the American Geriatrics Society, 41, 747-752.

Innes, C. R. H., Jones, R. D., Dalrymple-Alford, J. C., Hayes, S., Hollobon, S., Severinsen, J., ET AL. (2007). Sensory-motor and cognitive tests predict driving ability of persons with brain disorders. Journal of the Neurological Sciences, 260, 188-198.

JoHnson, J. E. (1999). Urban older adults and the forfeiture of a driver's license. Journal of Gerontological Nursing, 25, 12-18.

JONES, R. D. (2006). Measurement of sensory-motor control performance capacities: Tracking tasks. In J. D. Bronzino (Ed.), The biomedical engineering handbook: Biomedical engineering fundamentals (pp. 77-1 to 77-25). Boca Raton, FL: Taylor \& Francis.

Jones, R. D., \& DonaldSon, I. M. (1995). Fractionation of visuoperceptual dysfunction in Parkinson's disease. Journal of the Neurological Sciences, 131, 43-50.

Jones, R. D., Donaldson, I. M., \& Parkin, P. J. (1989). Impairment and recovery of ipsilateral sensory-motor function following unilateral cerebral infarction. Brain, 112, 113-132.

Jones, R. D., Donaldson, I. M., Parkin, P. J., \& Coppage, S. A. (1990). Impairment and recovery profiles of sensory-motor function following stroke: Single-case graphical analysis techniques. International Disability Studies, 12, 141-148.

Jones, R. D., Donaldson, I. M., \& Sharman, N. B. (1996). A technique for removal of the visuoperceptual component from tracking performance and its application to Parkinson's disease. IEEE Transactions on Biomedical Engineering, 43, 1001-1010.

Jones, R. D., Donaldson, I. M., \& Timmings, P. L. (1992). Impairment of high-contrast visual acuity in Parkinson's disease. Movement Disorders, 7, 232-238.

Jones, R. D., Sharman, N. B., Watson, R. W., \& Muir, S. R. (1993). A PC-based battery of tests for quantitative assessment of upper-limb sensory-motor function in brain disorders. Proceedings of the 15th Annual International Conference of IEEE, 15, 1414-1415.

Jones, R. D., White, A. J., Lawson, K. H. C., \& Anderson, T. J. (2002). Visuoperceptual and visuomotor deficits in developmental stutterers: An exploratory study. Human Movement Science, 21, 603-619.

Jones, R. D., Williams, L. R. T., \& Wells, J. E. (1986). Effects of laterality, sex, and age on computerized sensory-motor tests. Journal of Human Movement Studies, 12, 163-182.

Korteling, J. E. (1990). Perception-response speed and driving capabilities of brain-damaged and older drivers. Human Factors, 32, 95-108.

Land Transport Safety Authority (2002). Medical aspects of fitness to drive. Wellington, New Zealand: Author.

Legh-Smith, J., Wade, D. T., \& Hewer, R. L. (1986). Driving after a stroke. Journal of the Royal Society of Medicine, 79, 200-203.

Lewis, D. A., Kamon, E., \& Hodgson, J. L. (1986). Physiological differences between genders: Implications for sports conditioning. Sports Medicine, 3, 357-369.

LeZAK, M. D. (1995). Neuropsychological assessment (3rd ed.). New York: Oxford University Press.

Lings, S., \& Jensen, P. B. (1991). Driving after stroke: A controlled laboratory investigation. International Disability Studies, 13, 74-82.

LundQvist, A., Gerdle, B., \& RönNBERG, J. (2000). Neuropsychological aspects of driving after a stroke - in the simulator and on the road. Applied Cognitive Psychology, 14, 135-150.

MaZer, B. L., Korner-Bitensky, N. A., \& Sofer, S. (1998). Predicting ability to drive after stroke. Archives of Physical Medicine \& Rehabilitation, 79, 743-750.
McKenna, P., Jefferies, L., Dobson, A., \& Frude, N. (2004). The use of a cognitive battery to predict who will fail an on-road driving test. British Journal of Clinical Psychology, 43, 325-336.

McKnight, A. J., \& McKnight, A. S. (1999). Multivariate analysis of age-related driver ability and performance deficits. Accident Analysis \& Prevention, 31, 445-454.

Muir, S. R., Jones, R. D., Andreae, J. H., \& Donaldson, I. M. (1995). Measurement and analysis of single and multiple finger tapping in normal and Parkinsonian subjects. Parkinsonism \& Related Disorders, 1, 89-96.

Myers, R. S., Ball, K. K., Kalina, T. D., Roth, D. L., \& Goode, K. T. (2000). Relation of useful field of view and other screening tests to on-road driving performance. Perceptual \& Motor Skills, 91, 279-290.

Nouri, F. M., Tinson, D. J., \& Lincoln, N. B. (1987). Cognitive ability and driving after stroke. International Disability Studies, 9, 110-115.

Peiris, M. T. R., Jones, R. D., Davidson, P. R., Carroll, G. J., \& BonEs, P. J. (2006). Frequent lapses of responsiveness during an extended visuomotor tracking task in non-sleep-deprived subjects. Journal of Sleep Research, 15, 291-300.

Robertson, I. H., Ward, T., Ridgeway, V., \& Nimmo-SMith, I. (1996). Structure of normal human attention: The Test of Everyday Attention. Journal of the International Neuropsychological Society, 2, 525-534.

Schanke, A.-K., \& Sundet, K. (2000). Comprehensive driving assessment: Neuropsychological testing and on-road evaluation of brain injured patients. Scandinavian Journal of Psychology, 41, 113-121.

Staplin, L., Gish, K. W., Decina, L. E., Lococo, K. H., \& McKnight, A. S. (1998). Intersection negotiation problems of older drivers: Vol. 1. Final technical report. Washington, DC: Office of Research and Traffic Records.

StatSoft (2003). Electronic statistics textbook. Available from www .statsoft.com/textbook/stathome.html.

TAYLOR, B. D., \& TRIPODES, S. (2001). The effects of driving cessation on the elderly with dementia and their caregivers. Accident Analysis \& Prevention, 33, 519-528.

Wang, C. C., Kosinski, C. J., Schwartzberg, J. G., \& Shanklin, A. V. (2003). Physician's guide to assessing and counseling older drivers. Washington, DC: National Highway Traffic Safety Administration.

Watson, R. W., Jones, R. D., \& Sharman, N. B. (1997). Twodimensional tracking tasks for quantification of sensory-motor dysfunction and their application to Parkinson's disease. Medical \& Biological Engineering \& Computing, 35, 141-145.

WILD, K., \& CotrelL, V. (2003). Identifying driving impairment in Alzheimer disease: A comparison of self and observer reports versus driving evaluation. Alzheimer Disease \& Associated Disorders, 17, 27-34.

Wilson, T., \& SMith, T. (1983). Driving after stroke. International Rehabilitation Medicine, 5, 170-177.

Wiseman, E. J., \& Souder, E. (1996). The older driver: A handy tool to assess competence behind the wheel. Geriatrics, 51, 36-38, 41-42, 45.

Wood, J. M., Worringham, C., Kerr, G., Mallon, K., \& Silburn, P. (2005). Quantitative assessment of driving performance in Parkinson's disease. Journal of Neurology, Neurosurgery, \& Psychiatry, 76, 176-180.

YounG, F. W. (1985). Multidimensional scaling. In S. Kotz, N. L. Johnson, \& C. B. Read (Eds.), Encyclopedia of statistical sciences. New York: Wiley.

\section{NOTE}

1. Detailed information on the sensory-motor and cognitive tests (SMCTests) can be found in the Canterbury Driving Assessment Tool (CanDAT) incorporating SMCTests version 5.0: User manual (Christchurch Neurotechnology Research Programme, 2006). An electronic version of this user manual can be downloaded from www .neurotech.org.nz/files/CanDAT_SMCTests_User_Manual.pdf or obtained directly from the authors.

(Manuscript received June 17, 2008; revision accepted for publication October 6, 2008.) 